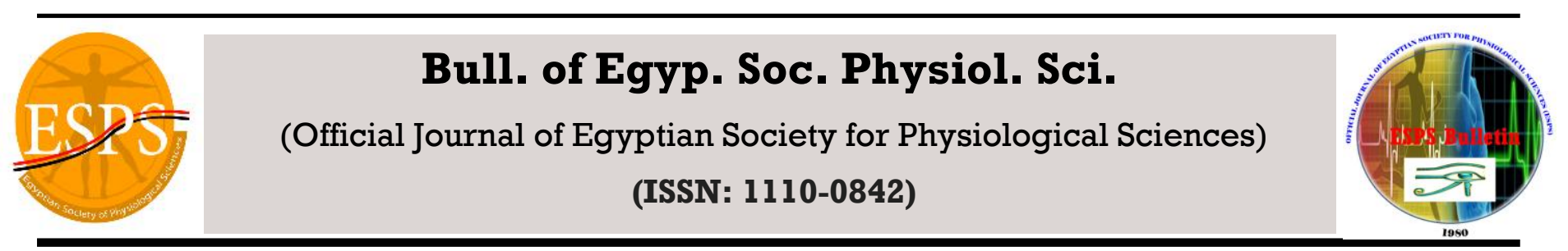

\title{
Protective effect of Multivitamin Complex on Copper Oxide nanoparticles $($ nanoCuO) induced toxicity in rats
}

\author{
Elhussainy M.A. Elhussainy ${ }^{1}$, Safinaz El-Shourbagy ${ }^{2}$ \\ ${ }^{1}$ Departments of Physiology, Faculty of Medicine, Kafrelsheikh University, 33516 Kafrelsheikh, Egypt. \\ ${ }^{2}$ Department of Pathology, Faculty of Medicine, Tanta University, 31527 Tanta, Egypt
}

Received: XXXXX Accepted: XXXXX Available online: $\mathrm{XXX}$

\section{Keywords}

- Multivitamin complex

- Vitamins-E, C, and A

- Nanoparticles toxicity

- Antioxidants

\section{Abstract}

The aim of this work was designed to investigate the effects of Multivitamin complex (MVC) on Copper oxide nano particles (nanoCuO)induced hepatotoxicity and nephrotoxicity in rats and its possible mechanism of action. The present study was performed on a forty male albino rats which were divided into four groups. Control group, MVC treated group, received Vitamins - E, C, and $\mathrm{A}$ in a dose of $130 \mathrm{mg} / \mathrm{kg}$ daily by intraperitoneal injection for 2 weeks. Nano $\mathrm{CuO}$ induced toxic group, this group received $\mathrm{CuO}$ nanoparticles (40-56nm)in a dose of $10 \mathrm{mg} / \mathrm{kg}$ daily by intraperitoneal injection for 2 weeks.MVC treated toxic group, this group received MVC in a dose of $130 \mathrm{mg} / \mathrm{kg}$ daily by intraperitoneal injection one hour before nanoCuO injection for 2 weeks. Multivitamin Complex caused significant decrease in serum levels of ALT, AST, blood urea and serum creatinine compared to nanoCuO-induced toxic group. MVC caused significant increase in serum levels of albumin compared to nanoCuO-induced toxic group. Multivitamin Complex caused significant decrease of malondialdehyde and nitric oxide levels and significant increase in superoxide dismutase and reduced glutathione levels compared to nanoCuO toxic group.MVC improved hepatic and renal structures by histopathological examination as it caused significant decrease in fatty changes in hepatocytes, congestion, and damage of renal tubules. The results suggest that Multivitamin Complex has potential protective role against $\mathrm{CuO}$ nanoparticles induced hepatotoxicity and nephrotoxicity by an antioxidant mechanism.

Corresponding author: Elhussainy M.A. Elhussainy, Department of Physiology, Faculty of Medicine, Kafrelsheikh University, Egypt.Tel: 01145350937 e-mail:elhussainy1970@yahoo.com 


\section{INTRODUCTION}

The growing field of nanotechnology has transformed many sectors of the industrial field with their breakthrough applications in the areas of biotechnology, electronics, material science, aerospace engineering, biosensors, cosmetics and medicinal drug delivery. Their novel physicochemical, thermal and electrical properties facilitate their application in clothing, medicine, and cosmetics thereby increasing the probability for human and environmental contact with these nano-materials [1].Metal oxides like; titanium dioxide $\left(\mathrm{TiO}_{2}\right)$, cupric oxide $(\mathrm{CuO})$, and zinc oxide have gained attention owing to their commercial usage. Metal oxide particles can undergo surface modification for better stability and binding to other substrates. Such widespread applications are attributable to their electrochemical and physical properties reflecting their small sizes and reactive surfaces [2].

Most researches to date have suggested that generation of reactive oxygen species (ROS) with consequent oxidative stress are frequently observed with NP toxicity [3]. Exposures to metal oxide nanoparticles were reported to induce tissue damage and abnormal cellular stress response via lipid peroxidation $[4,5]$.

The physicochemical characterization of NP including particle size, surface charge, and chemical composition is a key indicator for the resulting ROS response and NP-induced injury. NP-mediated ROS responses have been reported to orchestrate a series of pathological events such as genotoxicity, inflammation, fibrosis and carcinogenesis. For instance, Cho et al.[6] suggested that nanoCuO induced oxidative stress triggers cell signaling pathways resulting in increased expression of pro-inflammatory cytokines. Manna et al. [7] reported that exposure to nano copper oxide in particular; elicit ROSmediated cell death via mitochondrial dysfunction.

Cytotoxicity and apoptosis caused by nanoparticles have been implicated as a major mechanism of cell death caused by NP-induced oxidative stress [8]. Among the different apoptotic pathways, the intrinsic mitochondrial apoptotic pathway plays a major role in metal oxide NPinduced cell death since mitochondria are one of the major target organelles for NP-induced oxidative stress [9]. High levels of ROS in the mitochondria can result in damage to membrane phospholipids inducing mitochondrial membrane depolarization [10].The oxidative stress is achieved via a small proportion of electrons that escapes the mitochondrial chain and interacts with molecular oxygen to form $\mathrm{O}_{2}-$ which later gives rise to $\mathrm{H}_{2} \mathrm{O}_{2}$ or partially reduces to the damaging $\mathrm{OH} \cdot \mathrm{NP}$ can catalyze the $\mathrm{O}_{2}-$ generation either by blocking the electron transport chain or accelerating electron transfer to molecular oxygen [11].

Glutathione, (GSH) a potent free-radical scavenger, is responsible for maintaining the cellular redox state and protecting cells from oxidative damage [12]. NP-triggered free radicals consume the reduced glutathione (GSH) changing it into oxidized form glutathione disulfide (GSSG), thereby contributing to oxidative stress, apoptosis, and sensitization to oxidizing stimuli $[13,14]$. A part from GSH, NP-induced ROS modulate the 
antioxidant activities of ROS-metabolizing enzymes including NADPH-dependent flavor enzyme, catalase, glutathione peroxidase, and superoxide dismutase [15].

Exogenous antioxidants like vitamin $\mathrm{C}$, vitamin $\mathrm{E}$, and beta carotene or vitamin A are among the most widely studied dietary antioxidants [16]. Vitamin $\mathrm{C}$ is considered the most important water-soluble antioxidant in extracellular fluids. Vitamin E, a major lipid-soluble antioxidant is the most effective chain-breaking antioxidant within the cell membrane and is believed to be the primary free radical scavenger where it protects membrane fatty acids from lipid peroxidation $[17,18]$.

Therefore, the present study was carried out to investigate the alteration in hepatic and renal biochemical parameters and histopathological alterations induced by $\mathrm{CuO}$ nanoparticles in male rats and a trial to introduce a protection against their harmful effects by using Multivitamin Complex (vitamins E, C and A) which are well established as antioxidants to alter the oxidative damage, hepatotoxic and nephrotoxic effects of CuOnano particles.

\section{MATERIALS AND METHODS}

\subsection{Material:}

Copper oxide nanoparticles were obtained from Nano-Technology Centre, Faculty of Science, Kafrelsheikh University, Egypt. The size of nanoCuO was $40-56 \mathrm{~nm}$. Nano copper oxide was dissolved in distilled water to get the desired concentration which is $10 \mathrm{mg} / \mathrm{kg}$ and was administered by intraperitoneal injection daily for two weeks. This dose was determined based on the biological action of modified nanoparticles are 2 times more biologically active than the unmodified copper nanoparticles as the pharmacotoxic action of unmodified copper nanoparticles begins from dosage $25 \mathrm{mg} / \mathrm{kg}$, while $\mathrm{LD}_{50}$ is $45 \mathrm{mg} / \mathrm{kg}$ and $\mathrm{LD}_{100}$ is $60 \mathrm{mg} / \mathrm{kg}$. While toxicity of copper nanoparticles modified by oxygen $(\mathrm{CuO})$, which we used in our research, begins from dosage $10 \mathrm{mg} / \mathrm{kg}, \mathrm{LD}_{50}$ is $15 \mathrm{mg} / \mathrm{kg}$, $\mathrm{LD}_{100}$ is $30 \mathrm{mg} / \mathrm{kg}$.

Multivitamin complex is composed of a combination of vitamin A which is $\beta$-carotene 20 $\% 10 \mathrm{mg} / \mathrm{kg}$ (equivalent to $1500 \mathrm{IU}$ vitamin $\mathrm{A}$ ), (it was obtained from Sigma Company for Interpharma UK),Vitamin C90 mg/kg, (Kahira Pharm. Chem. Co. Egypt).Vitamin E or $\alpha$ tocopherol succinate $30 \mathrm{mg} / \mathrm{kg}$ (equivalent to 35 IU vitamin E)(Sigma).(Fat soluble vitamins-E, and A) were dissolved in sesame oil [19], while vitamin $\mathrm{C}$ was dissolved in distilled water and each was delivered to rats via intraperitoneal injection daily for two weeks.

\subsection{Animal}

Forty adult male albino rats, weighing $175 \pm 25 \mathrm{~g}$ were used in the experiments. They were acclimated in the controlled environment (temperature: $24 \pm 1{ }^{\circ} \mathrm{C}$; humidity: $65 \pm 10$ ) with free access to water and a food. All animal experiments were performed in compliance with the local ethics committee at animal house of Zoology Department, Faculty of Science, Tanta University, Tanta, Egypt. The rats were acclimatized to housing conditions for one week before starting the experiment. Animals were 
randomly divided into four groups each group contains of 10 rats.

Group 1: (control group) received daily normal saline only by intraperitoneal injection.

\section{Group 2:(Multivitamin complex treated group)} received only Vitamins-E, C, and A in a dose of $130 \mathrm{mg} / \mathrm{kg}$ daily for two weeks by intraperitoneal injection.

Group 3:(Nano $\mathrm{CuO}$ induced toxic group), this group received $\mathrm{CuO}$ nanoparticles $(\mathrm{nanoCuO})$ in a dose of $10 \mathrm{mg} / \mathrm{kg}$ daily for two weeks by intraperitoneal injection[20].

Group 4:(MVC pretreated toxic group), this group received pretreatment with MVC in a dose of $130 \mathrm{mg} / \mathrm{kg}$ daily for two weeks by intraperitoneal injection, one hour before intraperitoneal nanoCuO injection.

\section{Methodology:}

\section{Biochemical analyses}

\section{Sample preparation}

After 2 weeks of feeding and drug administration, rats were fasted overnight, and anesthetized with sodium pentobarbital $(40 \mathrm{mg} / \mathrm{kg}$ i.p.). A $2-\mathrm{ml}$ blood sample was collected by cardiac puncture. Serum was separated by centrifugation at $10,000 \mathrm{~g}$ $\left(4^{\circ} \mathrm{C}\right)$ for $15 \mathrm{~min}$ and serum was frozen at $-70{ }^{\circ} \mathrm{C}$ in aliquots until biochemical analysis were performed.

\section{Evaluation of biochemical parameters}

Serum levels of albumin, ALT, AST, blood urea, serum creatinine and serum nitric oxide (NO) were measured. In addition, malondialdehyde MDA or (TBARS), superoxide dismutase (SOD), and reduced glutathione (GSH) levels in liver and kidney tissues and red blood cells were determined.
Liver and kidney tissues were removed and washed with phosphate buffered saline (PBS), $\mathrm{pH}$ 7.4 , containing $0.16 \mathrm{mg} / \mathrm{ml}$ of heparin to remove any red blood cells and clots [21].Liver and kidney tissues were homogenized with an ultrasonic homogenizer. The homogenates were centrifuged at $10,000 \mathrm{~g}$ for 10 minutes at $4^{\circ} \mathrm{C}$ and the supernatant was obtained for measurement estimation of different antioxidants and lipidperoxides. The total protein levels for homogenates were estimated by the Biuret method [22].The homogenates were put in cold phosphate buffer, $\mathrm{pH} 7.0$ with ethylenediamine-tetra-acetic acid (EDTA), for TBARS measurement and cold $20 \mathrm{mM} \quad \mathrm{N}$-(2-hydroxyethyl) piperazine-N'-2ethanesulfonic acid (HEPES) buffer, pH 7.2, containing $1 \mathrm{mM}$ ethyleneglycol-bis (2aminoethoxy)-tetra-acetic acid (EGTA), $210 \mathrm{mM}$ mannitol, and $70 \mathrm{mM}$ sucrose for SOD measurement [23]. The supernatant was put in separate tubes and stored at $-70{ }^{\circ} \mathrm{C}$. Two milliliters of blood was separated into plasma and erythrocytes by centrifugation at $10,000 \times \mathrm{g}$ for 10 $\min$ at $4{ }^{\circ} \mathrm{C}$. The erythrocyte samples were washed three times with cold physiological saline (PS) and then hemolyzed by adding a fourfold volume of ice cold high-performance liquid chromatography (HPLC)-grade water. Hemolyzed erythrocyte samples were centrifuged at $10,000 \times \mathrm{g}$ for $10 \mathrm{~min}$ at $4{ }^{\circ} \mathrm{C}$, and the supernatant was collected and stored at $-70{ }^{\circ} \mathrm{C}$ for measurement of enzymatic activity. It is known that antioxidant enzymatic activity is stable in hemolysates stored under such conditions [24].

\section{Thiobarbituric acid reactive substances (TBARS)}

Lipid peroxidation levels were measured by the thiobarbituric acid (TBA) reaction using the 
method of Ohkawa et al. [25]. TBARS levels were expressed as nmol/mg protein in liver and kidney and as nmol/g hemoglobin in erythrocyte hemolysates.

\section{Superoxide dismutase (SOD) Activity Determination}

SOD activity in the tissue supernatants or the blood was measured according to Sun et al. [26]. The calculated SOD activity was expressed as $\mathrm{U} / \mathrm{mg}$ protein in liver, kidney, and as $\mathrm{U} / \mathrm{g}$ hemoglobin in erythrocyte hemolysates.

\section{Reduced glutathione (GSH) determination}

GSH levels were estimated according to the method of Jollow et al. [27]. The results were expressed as micromoles of GSH per milligram of protein.

\section{Nitric oxide (NO) determination}

The production of NO was determined indirectly by measuring the nitrite levels based on the Griess reaction according to Cortas and Wakid, [28].

\section{Liver function tests determination}

$A L T$ and AST were measured by colorimetric method according to Schmidt, [29], serum albumin was measured by colorimetric determination according to Drupt, (30), serum creatinine was measured according to Henry, [31] and Blood urea was measured according to Patton and Crouch,(32).

\section{Histopathological examination:}

Liver and kidney tissues were prepared for histopathological examination in all groups as tissues were fixed in $10 \%$ formalin and embedded in paraffin blocks. Tissue sections were stained with hematoxylin-eosin (H \& E). The light microscope histological examination was done using 200 and 400 magnification power.

\section{Statistical analysis}

Statistical analyses were accomplished using the Statistical Product and Service Solutions (SPSS) computer program (version 13.0). All results were reported as means $\pm \mathrm{SD}$. The comparison of the results from the various experimental groups and their corresponding controls was carried out using a one-way analysis of variance (ANOVA) followed by multiple comparison procedures (LSD test). The Differences were considered statistically significant at probability level $\mathrm{p} \leq 0.05$.

\section{RESULTS}

In group 2 (MVC treated group), Multivitamin Complex (MVC)caused insignificant changes in serum levels of albumin, ALT, AST, blood urea, and serum creatinine $(\mathrm{P}>0.05)$ compared to control group (Table 1).

In group 3 (nanoCuO induced toxic group), $\mathrm{CuO}$ nanoparticles caused significant increase in serum levels of ALT, AST, blood urea, and serum creatinine $(\mathrm{P}<0.001)$ compared to control group. CuOnano particles caused significant decrease in serum levels of albumin ( $\mathrm{P}<0.001)$ compared to control group (Table 1). In group 4 (MVC treated toxic group),application of Multivitamin Complex caused significant reduction in serum levels of ALT, AST, blood urea, and serum creatinine( $\mathrm{P}$ $<0.001)$ and significant increase in serum levels of albumin $(\mathrm{P}<0.001)$ compared to nanoCuO induced toxic group (Table 1). 
Table (1): Effects of treatment with Multivitamin complex on nanoCuO induced toxicity on the serum levels of albumin, alanine aminotransferase (ALT), aspartate aminotransferase (AST), Blood urea and serum creatinine, in groups 1, 2, 3and 4

\begin{tabular}{|l|l|l|l|l|l|l|}
\hline Parameter & $\begin{array}{l}\text { Group 1 } \\
\text { Mean } \pm \text { SD }\end{array}$ & $\begin{array}{l}\text { Group 2 } \\
\text { Mean } \pm \text { SD }\end{array}$ & $\begin{array}{l}\text { Group 3 } \\
\text { Mean } \pm \text { SD }\end{array}$ & $\begin{array}{l}\text { Group 4 } \\
\text { Mean } \pm \text { SD }\end{array}$ & F value \\
\hline Albumin (gm/dl) & $3.97 \pm 0.27$ & $3.86 \pm 0.25$ & $2.71 \pm 0.36^{\mathrm{a}}$ & $3.34 \pm 0.32^{\mathrm{b}}$ & 35.195 & 0.001 \\
\hline ALT (U/L) & $27.7 \pm 3.6$ & $29.8 \pm 5.4$ & $68.3 \pm 8.4^{\mathrm{a}}$ & $51.4 \pm 1.1^{\mathrm{b}}$ & 58.336 & 0.001 \\
\hline AST (U/L) & $32.9 \pm 3.8$ & $31.3 \pm 4.7$ & $77.8 \pm 8.9^{\mathrm{a}}$ & $56.3 \pm 5.9^{\mathrm{b}}$ & 127.471 & 0.001 \\
\hline Blood urea (mg/dl) & $27.5 \pm 4.2$ & $30.9 \pm 4.6$ & $81.7 \pm 9.5^{\mathrm{a}}$ & $55.1 \pm 8.8^{\mathrm{b}}$ & 121.655 & 0.001 \\
\hline Creatinine (mg/dl) & $0.98 \pm 0.15$ & $1.06 \pm 0.13$ & $3.01 \pm 0.39^{\mathrm{a}}$ & $1.87 \pm 0.21^{\mathrm{b}}$ & 150.149 & 0.001 \\
\hline
\end{tabular}

Values are mean $\pm \mathrm{SD}, \mathrm{n}=10$, ANOVA: analysis of variance; $\mathrm{p}<0.05$. (a) indicates significant results of group 3 (nanoCuOtoxic group) vs control group (group 1) and (b) indicates significant results of group 4 (MVC treated toxic group) vs (nanoCuO toxic group) (group 3).
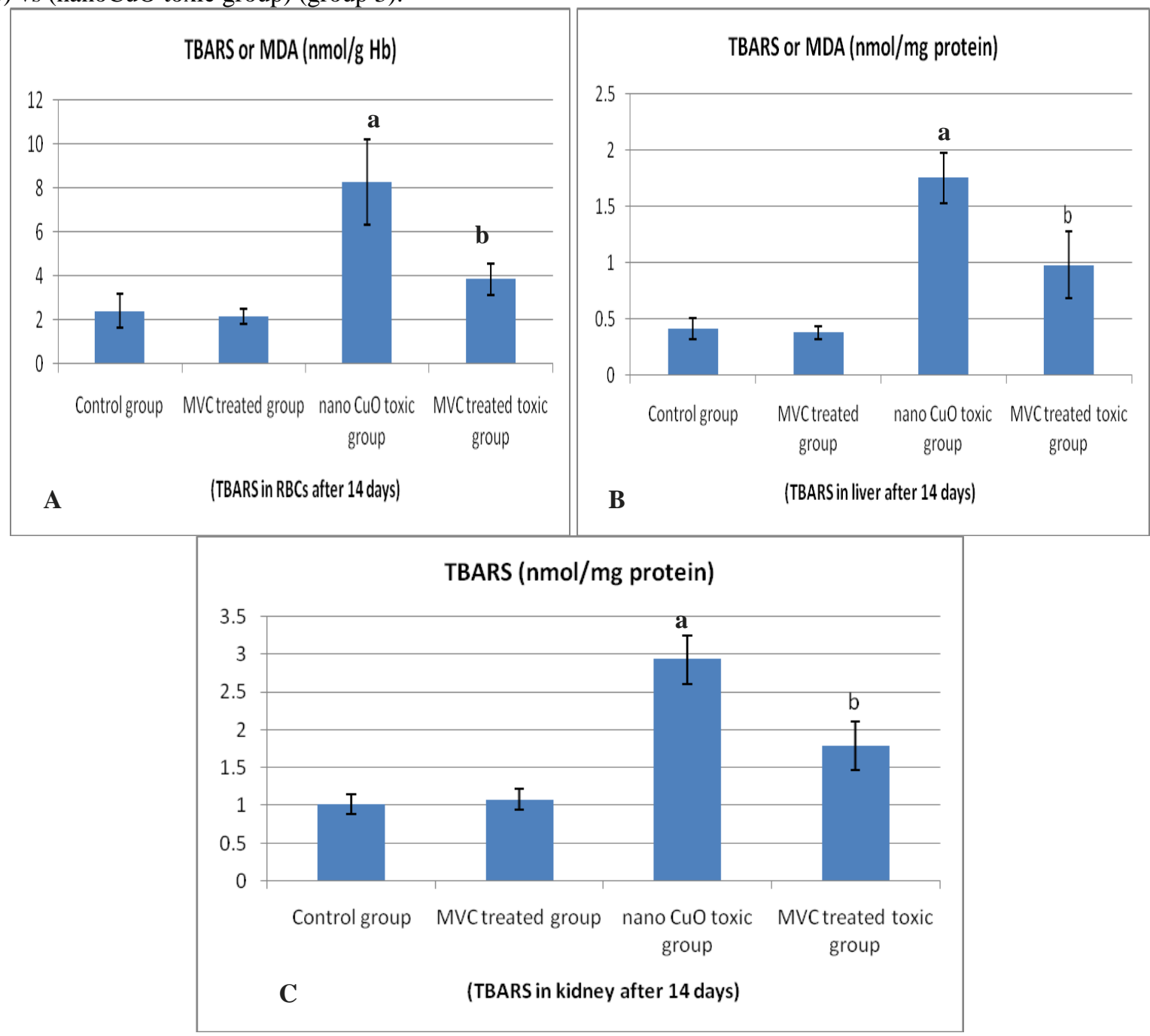

Fig. (1): Effect of $\mathrm{MVC}, \mathrm{CuO}$ induced toxicity and $\mathrm{MVC}$ pretreatment inCuO induced toxicity on TBARS or malondialdehyde (MDA) levels in RBCs (1A), liver (1B) and kidney tissues(1C) in the studied groups. "a" shows significant difference with thecontrol group in the same series. "b" shows significant difference with the $\mathrm{CuO}$ induced toxic group (allat $\mathrm{p}<0.05$ ). 

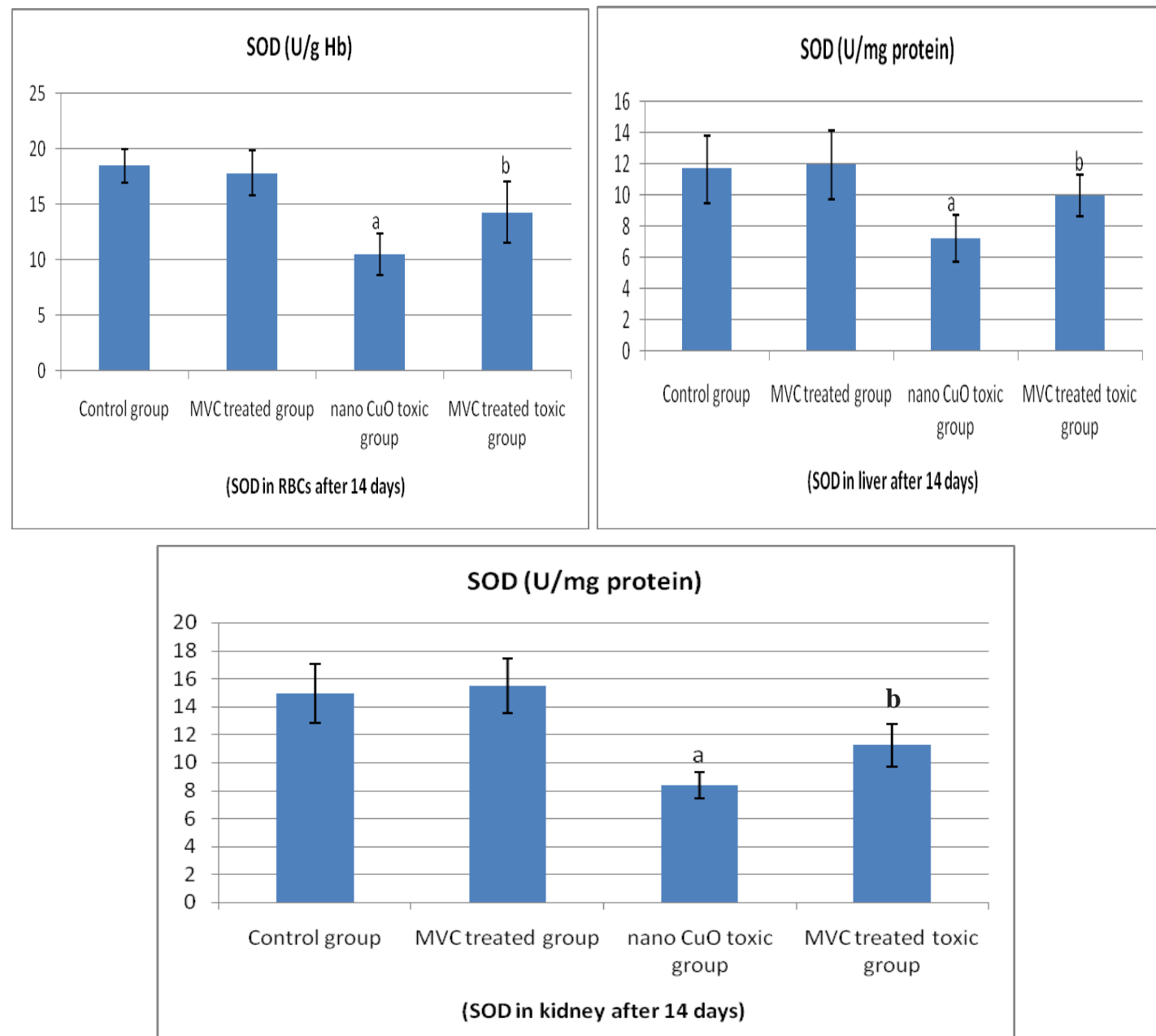

Fig. (2): Effect of MVC, $\mathrm{CuO}$ induced toxicity and $\mathrm{MVC}$ pretreatment in $\mathrm{CuO}$ induced toxicity on superoxide dismutase (SOD) levels in RBCs (2A), liver (2B) and kidney tissues (2C) in the studied groups. "a" shows significant difference with the control group in the same series. "b" shows significant difference with the $\mathrm{CuO}$ induced toxic group (all at $\mathrm{p}<0.05$ ).

As regard markers of oxidative stress and antioxidant enzymes; super oxide dismutase (SOD), reduced glutathione (GSH) and lipid peroxidation products (TBARS or MDA) in experimental rats were measured in blood, hepatic and renal tissues in figure 1 ( $\mathrm{A}, \mathrm{B}$ and $\mathrm{C}$ ), figure 2 (A, B and C) and figure 3 (A, B and C).

$\mathrm{CuO}$ nanoparticles administration alone (in group 3) promoted significant increase $(\mathrm{P}<$ $0.001)$ in TBARS and significant decrease $(P<$ 0.01) in the level of GSH and SOD enzyme activity in RBCs, liver and kidney tissues when compared to control rats. Pretreatment with $\mathrm{MVC}$ in $\mathrm{CuO}$ induced toxic rats (group 4) significantly increased the activities of tissues SOD and GSH levels and significantly decreased the blood and tissues levels of TBARS $(P<0.01)$ when compared to nano-CuO toxic rats. Administration of $\mathrm{MVC}$ alone in group 2 (in normal rats) showed insignificant changes $(P>0.05)$.

Concerning serum, hepatic and renal tissue nitric oxide (NO) levels (Fig.4A, B and C respectively), the nitrite levels in serum, hepatic and renal tissues in $\mathrm{CuO}$ nanoparticles administration significantly increased $(P<0.001)$ which was significantly decreased in 

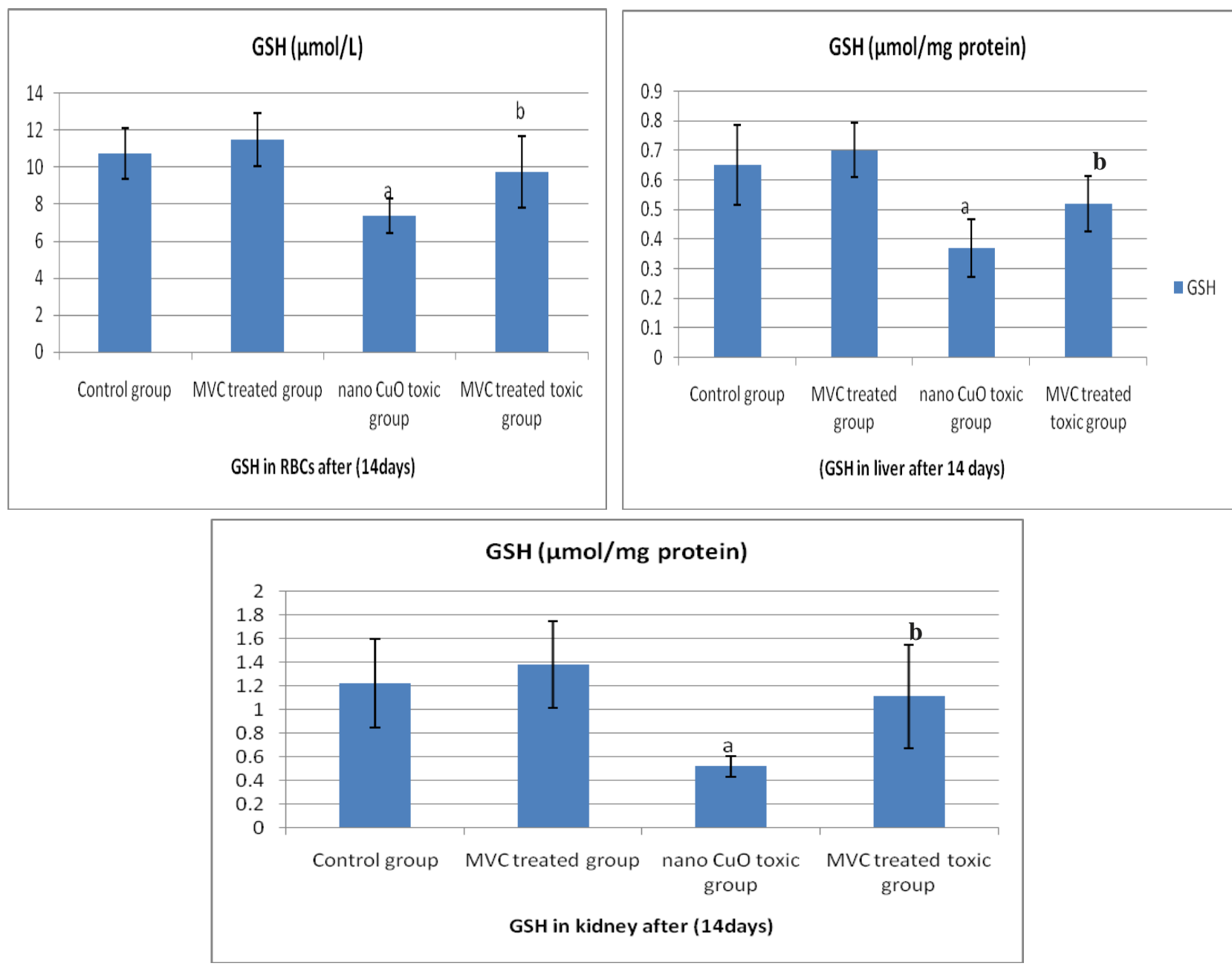

Fig. (3) Effect of MVC, $\mathrm{CuO}$ induced toxicity and $\mathrm{MVC}$ pretreatment in $\mathrm{CuO}$ induced toxicity on reduced glutathione (GSH) levels in RBCs (3A), liver (3B) and kidney tissues (3C) in the studied groups. "a" shows significant difference with the control group in the same series. "b" shows significant difference with the $\mathrm{CuO}$ induced toxic group (all at $\mathrm{p}<$ $0.05)$.

Table (2): Comparison between the studied experimental groups as regards the histopathological features of liver specimens.

\begin{tabular}{|l|c|c|c|c|}
\hline Parameters & Control group & MVC treated group & $\begin{array}{c}\text { Nano-CuO induced } \\
\text { toxic group }\end{array}$ & $\begin{array}{c}\text { MVC treated toxic } \\
\text { group }\end{array}$ \\
\hline Venous congestion & - & - & +3 & +2 \\
\hline Inflammation & - & - & +3 & +1 \\
\hline Fatty changes & - & - & +3 & +1 \\
\hline Necrosis of cells & - & - & +3 & +1 \\
\hline
\end{tabular}

$(-)$ absent, $(+1)$ mild presence, $(+2)$ moderate presence and (+3) strong presence

MVC pretreated rats $(P<0.001)$. However in group 2, insignificant changes were observed compared to control group $(P>0.05)$.

\subsection{Histopathological examination}

(Group 1) Control groups, as regard liver biopsy, showed normal lobular architecture (hepatic cells and portal tracts)(Fig. 5A). The renal tissues showed also, normal size and shape of glomeruli and normal renal tubules (Fig. 6A).

(Group 2) MVC treated group showed normal lobular architecture, normal hepatocytes, normal blood vessels within portal tracts and blood sinusoids (Fig. 5B). As regard kidney tissue also, 
showed normal renal glomeruli as regard shape and size (Fig. 6B).

(Group 3) $\mathrm{CuO}$ nanoparticles toxic group, as regard liver sections showed severely congested blood vessels within portal tracts, fatty changes in hepatocytes, inflammatory cellular infiltrations at the portal areas, and dot necrosis(Fig. 5C and 5D). Kidney biopsies showed marked congestion of blood vessels, vacuolization (hydropic degeneration) of some renal tubules and moderate atrophy of some glomeruli (Fig. 6C and 6D).
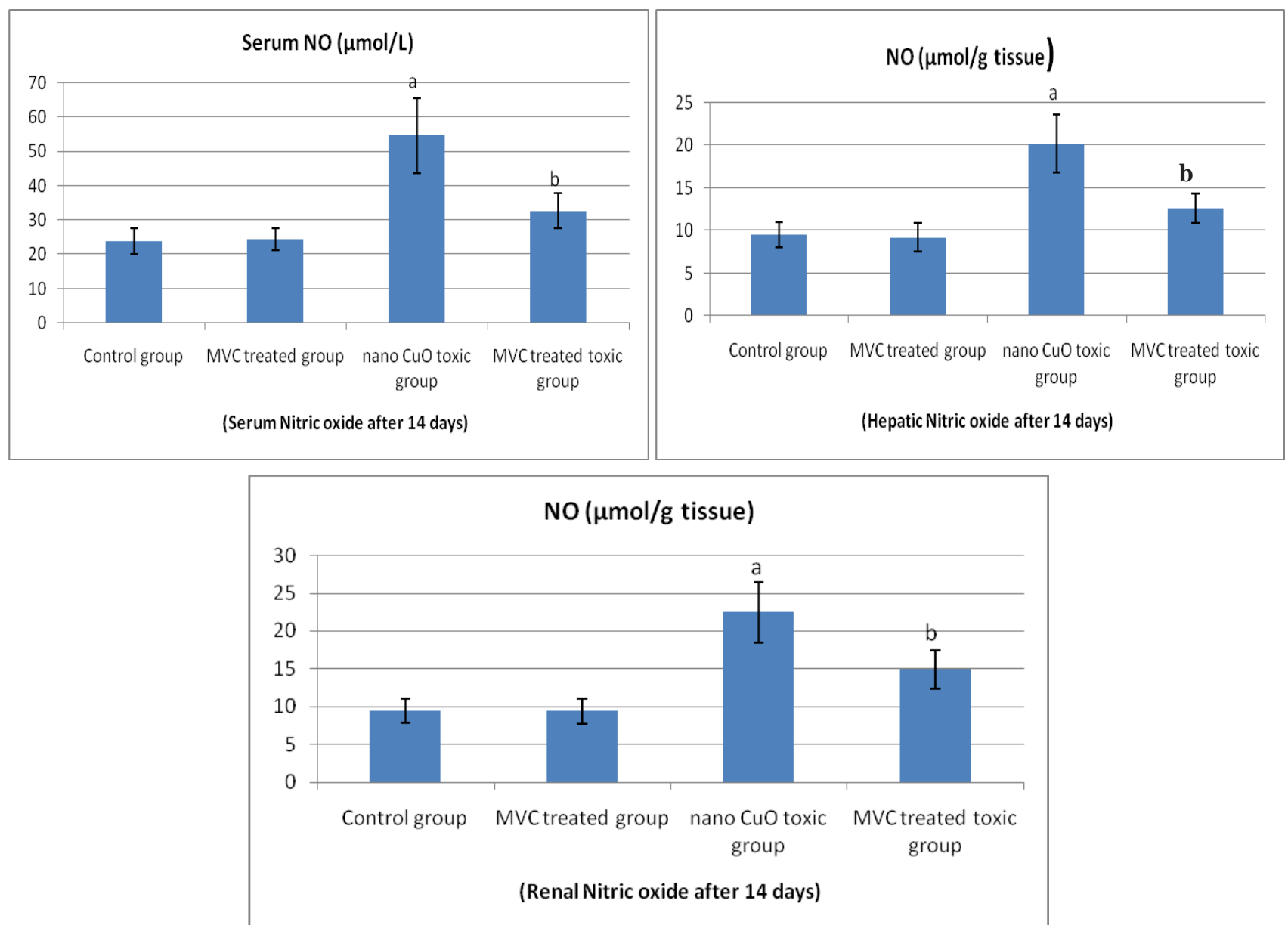

Fig. (4) Effect of MVC, $\mathrm{CuO}$ induced toxicity and MVC pretreatment in $\mathrm{CuO}$ induced toxicity on nitric oxide (GSH) levels in serum (4A), liver (4B) and kidney tissues (4C) in the studied groups. "a" shows significant difference with the control group in the same series. "b" shows significant difference with the $\mathrm{CuO}$ induced toxic group (all at $\mathrm{p}<0.05)$.

Table (3): Comparison between the studied experimental groups as regards the histopathological features of renal specimens.

\begin{tabular}{|l|c|c|c|c|}
\hline Parameters & Control group & MVC treated group & $\begin{array}{c}\text { Nano-CuO induced } \\
\text { toxic group }\end{array}$ & $\begin{array}{c}\text { MVC treated toxic } \\
\text { group }\end{array}$ \\
\hline $\begin{array}{l}\text { Renal vascular } \\
\text { congestion }\end{array}$ & - & - & +3 & +2 \\
\hline Renal tubular damage & - & - & +3 & +1 \\
\hline $\begin{array}{l}\text { Interstitial } \\
\text { inflammation }\end{array}$ & - & - & +3 & +1 \\
\hline Fatty degeneration & - & - & +3 & +1 \\
\hline Glomerular atrophy & & & +3 & - \\
\hline
\end{tabular}

(-) absent, (+1) mild presence, (+2) moderate presence and (+3) strong presence 
(Group 4) MVC treated toxic group, showed marked improvement in liver and kidney tissues as mild damage in hepatocytes, mild fatty degeneration, and mild congestion of blood vessels within portal tracts were observed (Fig. 5E and $5 \mathrm{~F})$. Also, renal tissues and tubules showed normal size and shape of glomeruli and mild congestion of blood vessels in the kidney (Fig. 6E and 6F).

\section{Discussion}

In the present study, we investigated the biochemical variation in the serum and liver to determine the hepatic injury induced by $\mathrm{CuO}$ NPs on some liver function tests. Our results revealed that an elevation in the serum levels of ALT and AST as well as the reduction in serum albumin level which suggested the presence of marked liver damage (hepatotoxicity), that further confirmed by hepatic degeneration and dot necrosis appeared in histopathological examination. Multivitamin complex (MVC) pretreatment in toxic rats revealed significant reduction in the serum levels ALT and AST while serum albumin level was significantly increased compared to nanoCuO induced toxic group. This was confirmed by marked improvement of hepatic cells and decrease congestion of blood vessels which appeared in histopathological examination.

In addition, the present study showed that nano$\mathrm{CuO}$ administration caused significant increase in the levels of blood urea and serum creatinine and their elevations suggested a renal dysfunction (nephrotoxicity). These findings were confirmed by renal tubular degeneration and atrophy of some glomeruli which were observed by histopathological examination. Multivitamin complex (MVC) pretreatment revealed significant reduction in the serum levels of urea and creatinine when it was daily administered for 2 weeks just before nanoCuO injection. This was confirmed by marked improvement of renal tissues and decrease congestion of blood vessels which observed by histopathological examination.

Results of the present study are in accordance with Chen et al.(33)who observed that nano- $\mathrm{Cu}$ induce impairment in the kidney and liver in mice. Also, Meng et al.(12) revealed that when mice were exposed to nano- $\mathrm{Cu}$, it would lead to metabolic changes and copper accumulation in the kidney. Lei et al.(13) also observed that nano-Cu could induce hepatotoxicity and nephrotoxicity, which manifested overt scattered hepatocellular necrosis and renal proximal tubule epithelial cellular necrosis in rats.

The mechanism by which $\mathrm{CuO}$ nanoparticles generated cytotoxicity to liver and kidney were due to their water soluble ions as $\mathrm{Cu}$ ions can be released from the surface of $\mathrm{CuO}$ nanoparticles. It has been proposed that $\mathrm{CuO}$ nanoparticles decrease cell viability by binding to DNA resulting in DNA damage and cell death(34, 35, 36).In addition, liver and kidney damage caused by $\mathrm{CuO}$ nanoparticles may be due to oxidative stress and lipid peroxidation as excessive nano copper accumulation in hepatocytes or nephrocytes would inevitably result in mitochondrial failure and cell death (37).Cho et al., 2012(6)suggested that the mechanism by which $\mathrm{CuO}$ NP caused cytotoxicity is increased pro-inflammatory cytokines, secretion of tumor necrosis factor alpha (TNF- $\alpha$ ), marked increase in the level of interleukin $1 \beta$ and interleukin 8 . 
In our study concerning malondialdehyde (MDA) or TBARS which indicate oxidative stress and lipid peroxidation, in red blood cells, hepatic and renal tissues, in group 2 (Multivitamin complex treated group) rats received only vitamins- E, C, and A, insignificant changes were observed compared to control group. In group 3 (nanoCuo induced toxic group) $\mathrm{CuO}$ nanoparticles administration

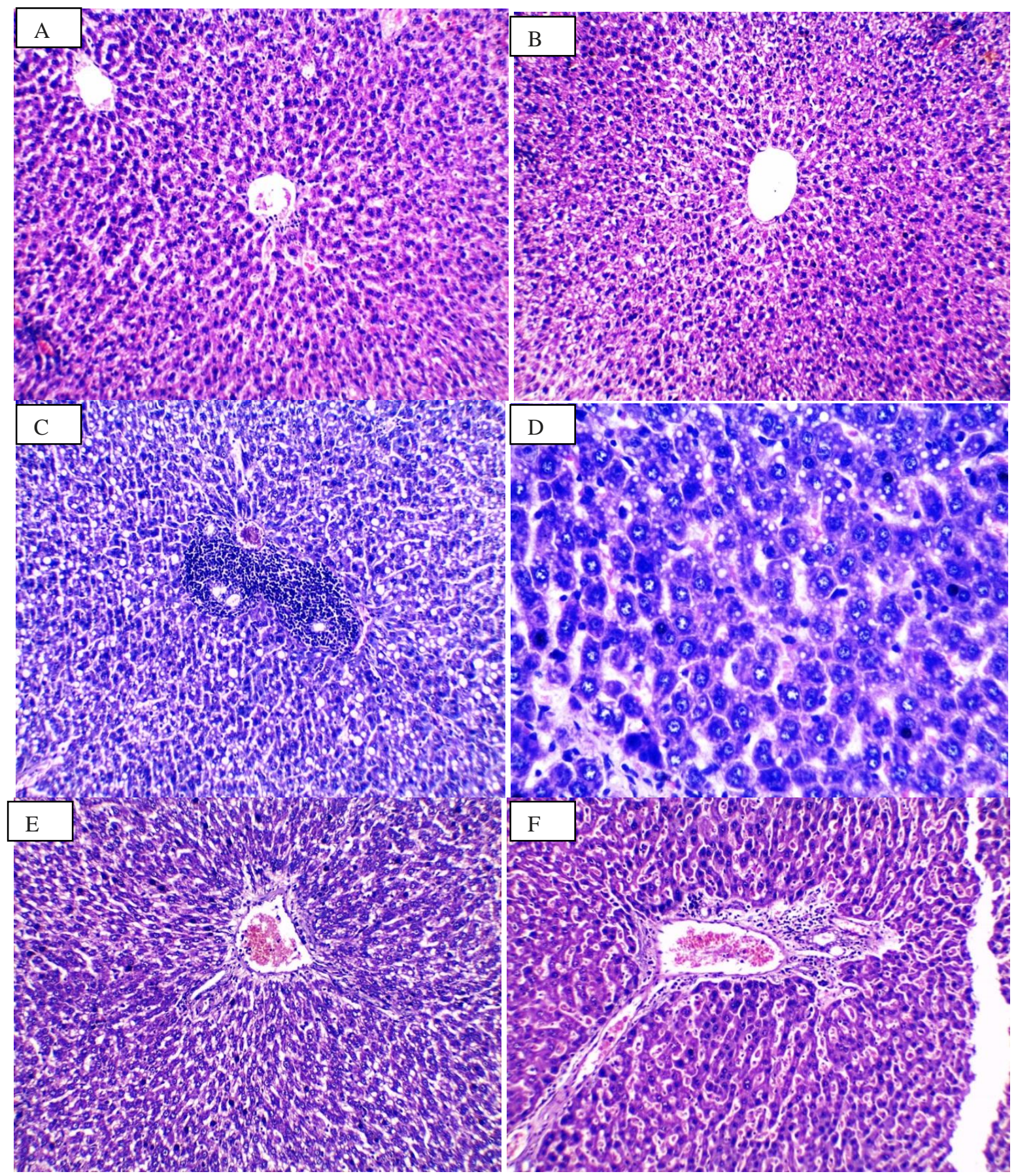

Fig. (5): Showing liver tissues from control group (fig 5A), MVC treated group (fig 5B), nanoCuO toxic group (fig 5C,D) and MVC treated toxic group (fig 5E, F) stained with with Haematoxiline \& Eosine (magnification is 200 in all slides except 5D x 400 magnification).

promoted significant increase in TBARS compared to control group. In group $4 \mathrm{MVC}$ pretreatment caused significant decreases in TBARS levels compared to nanoCuO induced 
toxic group. As regard endogenous antioxidants as superoxide dismutase (SOD), and reduced glutathione (GSH)in red blood cell, hepatic and renal tissues, in group 2 insignificant changes were observed compared to control group. In group 3,CuO nanoparticles administration promoted significant increase in SOD and GSH levels compared to control group. In group 4, MVC pretreatment promoted significant decreases in SOD and GSH levels compared to nanoCuO induced toxic group.

Also, several studies report alterations of renal function and pathological changes were observed in kidney tissues after exposure to copper nanoparticles [38]. The role of oxidative stress as a possible triggering mechanism for $\mathrm{CuO}$ NP inducing kidney damage was demonstrated by increased ROS generation, and enhanced lipid peroxidation [38], as well as reduction of antioxidant activities [39]. When reactive oxygen species (ROS, such as hydroxyl radical, superoxide, and so on) production overwhelms the antioxidant defense capacity of cell, it would lead to oxidative stress (40). ROS, as an important factor in the apoptotic process, can cause the disruption of the cell membrane and damage to protein, lipids, and DNA in a cell (41). Superoxide dismutase (SOD), one of the enzymatic scavengers of ROS, is reported to defense the oxidative stress (42).

Fahmy and Cormier,(37) observed that cells exposed to copper nanoparticles, level of catalase and glutathione reductase activity decreased and activity of glutathione peroxidase increased. Increased activity of glutathione suggests that copper nanoparticles not only produce free radical, but also they stop the cell antioxidant defense.

In the present study, vitamin $\mathrm{E}$ administration together with vitamin $\mathrm{C}$ and $\mathrm{A}$ showed an antiperoxidative and antioxidant effects in the rat liver and kidney tissues by significantly decreasing the nanoCuO-induced rise of hepatic and renal MDA levels and significant increase in superoxide dismutase and reduced glutathione in red blood cells, liver and kidney . This effect of vitamin $\mathrm{E}$ and other antioxidant vitamins may be explained by their direct free radical scavenging property, and preserving cellular integrity, they can protect against oxidative stress and lipid peroxidation which induce organ damage [18].

Nitric oxide (NO) has been reported to down regulate cytochrome P450 and to suppress liver protein and DNA synthesis, and these activities may contribute to hepatotoxicity caused by nanoparticles $(41,43)$.In the current study, $\mathrm{CuO}$ nanoparticles promoted significant increase in hepatic and renal NO production which was confirmed by histopathological examination which revealed marked congestion in blood vessels of liver and kidney tissues beside some inflammatory cellular infiltrates within portal tracts. While MVC pretreatment promoted significant decrease in the NO levels. Oxidative stress has been suggested to play an important role in the mechanisms of toxicity for a number of nanoparticles including copper oxide. In addition to the direct oxidative stress in hepatocytes induced by accumulation of $\mathrm{CuO}$ NPs, the activated Kupfer cells and recruited inflammatory cells mediated oxidative damage. So, a link between inflammation and oxidative stress where recruited inflammatory cells can 
generate oxidative stress by activating oxidative stress responsive transcription factors $(7,41)$.

In conclusion, our data suggest that CuOnano particles mediate hepatotoxicity and nephrotoxicity and that the preliminary mechanism might occur through the release of reactive oxygen species (ROS), and nitric oxide (NO) production. Multivitamin complex which is a combination of exogenous antioxidants including vitamins- $\mathrm{E}, \mathrm{C}$ and A protect both liver and kidney from toxicity induced by CuONPs. The results suggest that Multivitamin Complex have potential protective role against $\mathrm{CuO}$ nanoparticles induced hepatotoxicity and nephrotoxicity via an antioxidant mechanism.

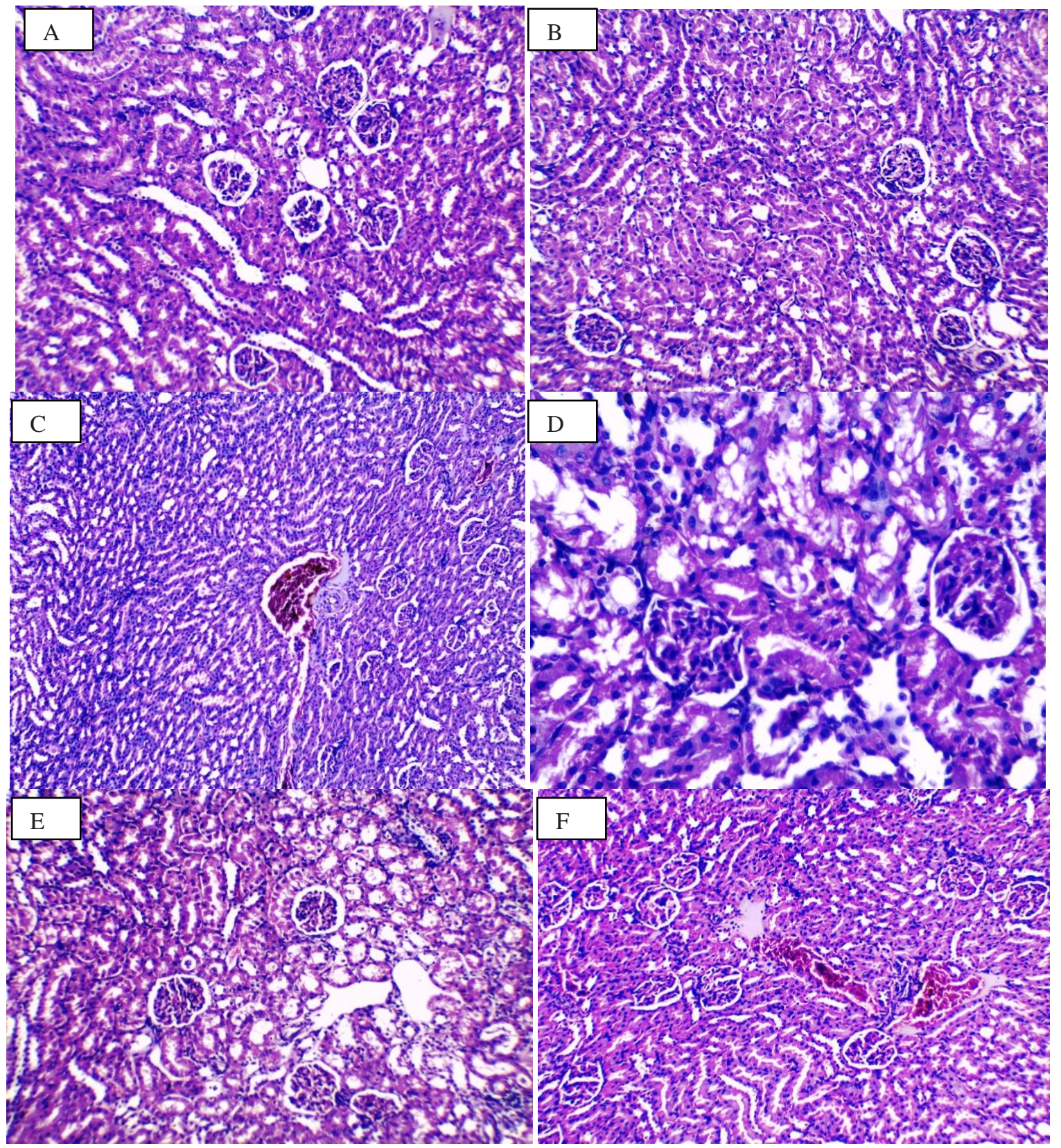

Fig. (6): Showing kidney tissues from control group (fig 6A), MVC treated group (fig 6B), nanoCuO toxic group (fig $6 \mathrm{C}, \mathrm{D}$ ) and MVC treated toxic group (fig 6E, F) stained with with Haematoxiline \& Eosine (magnification is 200 in all slides except 6D x 400 magnification). 


\section{Acknowledgments}

We would like to gratefully acknowledge Prof. Dr. Maged Elkemary, Nanotechnology Centre, Kafrelsheikh University for help and support.

\section{REFERENCES}

1.Donaldson K., Murphy F. A., Duffin R., and

Poland C. A.:"Asbestos, carbon nanotubes and the pleural mesothelium: areview of the hypothesis regarding the role of long fibre retentionin the parietal pleura, inflammation and mesothelioma,"Particle and Fibre Toxicology; 7: 5,2010 .

2. Poljak-Blazi M, Jaganjac M, Mustapic M, Pivac N, and Muck-SelerD,: "Acute immunemodulatory effects of iron poly-iso-maltosatein rats," Immunobiology;214(2): 121-128,2009.

3.Li N, Xia T, and Nel AE: "The role of oxidative stressin ambient particulate matter-induced lung diseases and itsimplications in the toxicity of engineered nanoparticles," FreeRadical BiologyandMedicine;44: 1689-1699, 2008.

4.Shukla RK, Sharma V, Pandey AK, Singh S, Sultana S, and Dhawan A: "ROS-mediated genotoxicity induced by titaniumdioxide nanoparticles in human epidermal cells," Toxicology inVitro,;25: 231-241, 2011.

5.Napierska D, Rabolli V, Thomassen L. C. J.: "Oxidativestress induced by pure and iron-doped amorphous silicananoparticles in subtoxic conditions," Chemical Research inToxicology, 25: 828-837, 2012.

6. Cho WS, Duffin R, Poland CA, Duschl A, Oostingh GJ, Macnee W, Bradley M, Megson IL, Donaldson K: Differential pro-inflammatory effects of metal oxide nanoparticles and their soluble ions in vitro and in vivo; zinc and copper nanoparticles, but not their ions, recruit eosinophils to the lungs. Nanotoxicology;6:22-35, 2012.

7. Manna P, Ghosh M, Das J, and Sil PC: "Contributionof nano-copper particles to in vivo liver dysfunction andcellular damage: role of $\mathrm{I} \kappa \mathrm{B} \alpha / \mathrm{NF}-\kappa \mathrm{B}$, MAPKs and mitochondrialsignal," Nanotoxicology, 6: 1-21, 2012.

8.Eom H, and Choi J. "p38 MAPK activation, DNA damage,cell cycle arrest and apoptosis as mechanisms of toxicity ofsilver nanoparticles in Jurkat T cells," Environmental Science andTechnology;44 (21): 8337-8342, 2010.

9.Xia T, Kovochich M, Brant J,: “Comparison of theabilities of ambient and manufactured nanoparticles to inducecellular toxicity according to an oxidative stress paradigm,"Nano Letters;6(8): 1794-1807, 2006.

10.Lenaz G. "The mitochondrial production of reactive oxygenspecies: mechanisms and implications in human pathology,"IUBMB Life; 52: 159-164, 2001.

11.Boonstra J and Post J. A.: "Molecular events associated withreactive oxygen species and cell cycle progression in mammaliancells," Gene;337:1-13, 2004.

12.Meng H, Chen Z, Xing G, Yuan H, Chen C, Zhao F, Zhang C, Zhao Y.: Ultrahigh reactivity provokes nanotoxicity:explanation of oral toxicity of nano-copper particles. ToxicolLett; 175(13):102-110, 2007.

13.Lei R, Wu C, Yang B, Ma H, Shi C, Wang Q, Yuan Y, Liao M.: Integrated metabolomic analysis of the nano-sizedcopper particle-induced hepatotoxicity and nephrotoxicityin rats: a rapid in vivo screening method for 
nanotoxicity.ToxicolApplPharmacol； 232(2):292301, 2008.

\section{Fenoglio I, Corazzari I, Francia C, Bodoardo} S, and Fubini B,:"The oxidation of glutathione by cobalt/tungsten carbide contributesto hard metalinduced oxidative stress," Free RadicalResearch; 42(8): 737-745, 2008.

15.Stambe C, Atkins R. C., Tesch G. H., Masaki T., Schreiner G. F., and Nikolic-Paterson D. J.:"The role of p38alpha mitogenactivatedprotein kinase activation in renal fibrosis," Journal ofthe American Society of Nephrology;15 (2): 370379,2004 .

16. Asplund K. Antioxidant vitamins in the prevention of cardiovascular disease: a systematic review. J Intern Med 2002; 251(5):372-92.

17. Gulec, M.; Gurel, A.; Armutcu, F. Vitamin E protects against oxidative damage caused by formaldehyde in the liver and plasma of rats, Mol Cell Biochem, 290, 61-67, 2006.

18.SushmaBharrhan, Kanwaljit Chopra and Praveen Rishi.Vitamin E Supplementation Modulates Endotoxin-induced Liver Damage in a Rat Model .Am. J. Biomed.Sci, 2(1), 51-62 2010.

19. Hedayat IS, and Azab KS. Effect of vitamin $\mathrm{E}$ and or nicotine on the activities of lactate dehydrogenase isoenzyme in serum of gamma irradiated rats. Biologia, Bratislava, 59/3: 347 353, 2004.

20. Bogoslovskaya OA, Sizova EA, Polyakova VS, Miroshnikov SA, Leipunsky IO, Olkhovskaya IP and GlushchenkoNN.: "The Study of Safe Introduction of Copper Nanoparticles with Different Physical-Chemical Characteristics into Organisms of Animals," Bulletin of OSU;32(2): 124-128, 2009.
21. Prasad K, Lee P, Mantha SV, Kalra J, Prasad M, Gupta JB: Detection of ischemiareperfusion cardiac injury by cardiac muscle chemi-luminescence. Mol Cell Biochem;115: 49$58,1992$.

22. Doumas BT, Bayse DD, Carter RJ, Peters T Jr, and Schaffer R.A: Candidate reference method for determination of total protein in serum. I. Development and validation. Clin Chem. 27: 1642-1650, 1981.

23. Mattiazzi M, D'Aurelio M, Gajewski CD, Martushova K, Kiaei M, Beal MF, Manfredi G: Mutated human SOD1 causes dysfunction of oxidative phosphorylation in mitochondria of transgenic mice. J BiolChem;277: 29626-29633, 2002.

24. Andersen HR, Nielsen JB, Nielsen F, Grandjean P:Antioxidative enzyme activities in human erythrocytes. ClinChem;43: 562-568, 1997.

25. Ohkawa H, Ohishi N, Yagi K: Assay for lipid peroxides in animal tissues by thiobarbituric acid reaction. Anal Biochem;95: 351-358, 1979.

26. Sun Y, Oberley LW, LI Y: A simple method for clinical assay of superoxide dismutase. ClinChem,34: 497-500, 1988.

27. Jollow, D.; Mitchell, L.; Zampaglione, N.; Gillete, J.: Bromobenzene induced liver necrosis: protective role of glutathione and evidence for 3 , 4-bromobenzenoxide as the hepatotoxic intermediate, Pharmacol; 11: 151-169, 1974.

28. Cortas NK, Wakid NW: Determination of inorganic nitrate in serum and urine by a kinetic cadmium-reduction method.;Clin Chem.;36: 1440-1443, 1990.

29.Schmidt E. Colorimetric method for determination of alanine aminotransferase Enzym. Biol. Clin. 3: 1, 1963. 
30. Drupt F.Colorimetric determination of serum albumin Pharm. Biol., 9: 777, 1974.

31. Henry R.J.ClinicalChemistry.Principle and techenics, $2^{\text {nd }}$ Edition, p.525, 1974.

32. Patton C.J., and Crouch S.R. Determination of blood urea.Anal. Chem., 49: 464, 1977.

33. Chen Z, Meng H, Xing G, Chen $\mathbf{C}$, Zhao Y, Jia G, Wang T, Yuan H, Ye C, Zhao F, Chai Z, Zhu C, Fang X, Ma B, Wan L.: Acute toxicological effects of copper nanoparticles in vivo. ToxicolLett;163(2):109-120, 2006.

34. Sizova E, Miroshnikov S, Polyakova V, Gluschenko N, Skalny A.: Copper Nanoparticles as Modulators of Apoptosis and Structural Changes in Tissues. Journal of Biomaterials and Nanobiotechnology, 3: 97-104, 2012.

35.Studer AM, Limbach LK, Van Duc L, Krumeich F, Athanassiou EK, Gerber LC, Moch H, Stark WJ: Nanoparticle cytotoxicity depends on intracellular solubility: comparison of stabilized copper metal and degradable copper oxide nanoparticles. ToxicolLett;197:169-174, 2010.

36.Cho W, Duffin R, Bradley M, Megson I, MacNee W, Lee JK, Jeong $J$ and Donaldson K.:Predictive value of in vitro assays depends on the mechanism of toxicity of metal oxide. Nanoparticles Particle and Fibre Toxicology; 10:55, 2013.

37.Fahmy B, Cormier SA.: Copper oxide nanoparticles induce oxidative stress and cytotoxicity in airway epithelial cells. Toxicology in Vitro;23: 1365-1371, 2009.

38.Sarkar A, Das J, Manna P, Sil PC:Nanocopper induces oxidative stress and apoptosis in kidney via both extrinsic and intrinsic pathways. Toxicology;290(2-3):208-217, 2011.
39.Gomes SI, Novais SC, Gravato C, Guilhermino L, Scott-Fordsmand JJ, Soares AM, Amorim MJ.:Effect of $\mathrm{Cu}$-nanoparticles versus one $\mathrm{Cu}$-salt: analysis of stress biomarkers response in Enchytraeusalbidus (Oligochaeta). Nanotoxicology;6:134-143, 2012.

40.Dreher KL.: Health and environmental impact of nanotechnology: toxicological assessment of manufactured nanoparticles. ToxicolSci;77(1):3-5, 2004.

41.Sharma V, Anderson D, Dhawan A.: Zinc oxide nanoparticles induce oxidative DNA damage and ROS-triggered mitochondria mediated apoptosis in human liver cells (HepG2). Apoptosis.;17:852-870, 2012.

42.Martindale JL, Holbrook NJ.: Cellular response to oxidative stress: signaling for suicide and survival. J Cell Physiol;192(1):1-15, 2002.

43. Manke A, Wang L, and Rojanasakull Y. Mechanisms of Nanoparticle-Induced Oxidative Stress and Toxicity. BioMed Research International, Volume (15) 1- 14, 2013. 